\title{
Attention effects of moving and stationary single- element and multiple-element precues: Limits of automaticity
}

\author{
MARYLOU CHEAL \\ Arizona State University, Tempe, Arizona \\ and \\ GARVIN CHASTAIN \\ Boise State University, Boise, Idaho
}

\begin{abstract}
A multiple-element precue (MEP), in which one unique element defines the actual precue, results in efficient precuing for identification of a target. The time course for identification in this case is similar to that for a central precue, even though it is presented peripherally (Chastain, 1996; Chastain \& Cheal, in press). Five experiments were conducted to gain further information on the function of MEPs and to question what advantage prior knowledge of the precue may give. In Experiments 1 and 2, it was shown that for "pop-out" features, accuracy of identification of a target was higher if the precue type was known in advance. In contrast, as shown in Experiments 3, 4, and 5, when the precue was defined by apparent motion, there was no difference in accuracy due to advanced knowledge of the precue. Further, accuracy was considerably better for motion precues than for stationary precues.
\end{abstract}

Attention appears to have many effects on visual perception, but how attention is allocated to stimuli or locations in the visual field still elicits considerable controversy. For instance, it has been shown that precuing attention to a target location can improve responses to targets at that location (Cheal \& Gregory, 1997; Cheal \& Lyon, 1989; Colegate, Hoffman, \& Eriksen, 1973; Müller \& Rabbitt, 1989; Nakayama \& Mackeben, 1989; Posner, 1980 ). New research suggests that attention to a target actually improves the veridicality of the perception (Prinzmetal, Nurachuku, Bodanski, Blumenfeld, \& Shimizu, 1977). In addition, it has been shown that attention to a different location in the visual field can result in inhibition at noncued locations (Cheal \& Gregory, 1997; Posner \& Cohen, 1984; Shiu \& Pashler, 1994). An area that needs further clarification is specification of the characteristics of a precue that are necessary for the elicitation of attention to a target location.

\section{Differences Between SEPs and MEPs}

In a large proportion of past research, single-element precues (SEPs), in which a single sudden onset in the pe-

Some of these data were presented by M.L.C. at the Western Attention Conference in Pomona, California, in June 1996. We thank Charles Folk, Arthur Kramer, and Jeremy Wolfe for comments on an earlier version of the manuscript. In addition, we acknowledge the assistance in data collection by Heidi Aldous, Ellen Boldman, Rich Davis, Amanda Gray, Meranda McArthur, Rebecca Norton, Stephanie Powell, and Stephanie Wright, and the statistical consultation of James Carbahal. Correspondence should be addressed to M. L. Cheal, 127 E. Loma Vista Drive, Tempe, AZ 85282-3574 (e-mail: cheal@asu.edu). riphery indicates the target location, have been used. Another type of precue is a multiple-element precue (MEP) in which elements are near each possible target location, and a singleton element, unique in some characteristic such as color or luminance, indicates the actual target location. With this precue, visual search is used to determine the location of the actual precue. Direct comparison of SEPs and MEPs is proving to be fruitful.

In order to investigate whether attention can be elicited automatically by an MEP, as it is by an SEP, Chastain and Cheal (in press) compared accuracy of target identification when the target location was precued either with an SEP or an MEP. In four experiments, they demonstrated several differences between SEPs and MEPs in which the precue was stationary; that is, once it appeared, it remained in the same location: (1) An SEP resulted in a rapid rise in accuracy for intervals between the precue and the target (stimulus onset asynchrony, SOA) up to $100 \mathrm{msec}$, whereas an MEP resulted in a much slower rise so that asymptote did not occur until about $300-\mathrm{msec}$ SOA. Some of this difference was likely due to the longer time needed to interpret the MEP and realize the location of the actual precue. (2) With an SEP, there was a decline in accuracy at long SOAs, but there was no decline at long SOAs with an MEP. (3) If the precue was irrelevant, accuracy on valid trials was better than accuracy on invalid trials when an SEP was used, but if an MEP was used, there was no difference between valid and invalid trials. In other work, Chastain (1996) demonstrated similar differences in the time course of attention effects between SEPs and MEPs in studies in which the unique precue differed in line orientation from the other elements on 
the screen. Thus, although differences in luminance may have affected the Chastain and Cheal color experiments (Theeuwes, 1995), such a difference in luminance for the color precues was not solely responsible for the results in their studies. It was concluded that MEPs require a voluntary allocation of attention to the cued location.

\section{Visual Search Part of Task}

The task used by Chastain and Cheal (in press) with MEPs is interesting in that it actually consists of two tasks. First, observers must locate the unique element that is the actual precue, and then they must identify the target that is at the location indicated by the unique element. The first component of the task (the detection of the precue) is a visual search task. In the experiments in Chastain and Cheal (in press), all of the precues were defined by what might be considered to be a featurein other words, the unique element that defined the actual precue (color, brightness, or line orientation) should pop out from the other elements, as in a typical search task.

One might expect that the processes of visual search would be the same in this case, as when only a speeded search response is required. That is, they would be consistent with feature integration (Treisman \& Gelade, 1980 ) or guided search theories (Wolfe, Cave, \& Franzel, 1989). Thus, the differences between SEPs and MEPs discussed above might not have been expected. The observers knew which feature would define the precue. Even so, the MEP did not elicit attention in the same manner as did the SEP. It took longer to determine the location of the actual precue with an MEP than it did with an SEP (Experiment 2 of Chastain \& Cheal, in press).

Perhaps these data support the conclusions of Jonides and Yantis (1988) that color or brightness allows attention to be voluntarily directed rather than the concept that stimuli that produce flat search functions (i.e., produce no increase in search time as a function of the number of distractors; Cheal \& Lyon, 1992a; Treisman, 1988) capture attention (Theeuwes, 1991, 1994).

Support for limitations on the ability of parallel searches (those that produce flat functions) to guide serial search comes from several directions. Wolfe et al. (1990) found that search for a color $\times$ color conjunction (i.e., a red/ green target in red/blue and green/blue distractors) or an orientation $\times$ orientation conjunction (i.e., a target made of a vertical and an oblique line in distractors that consist of either horizontal and oblique lines or horizontal and vertical lines) was not efficient. This was not just due to a more difficult search; a search for color $X$ orientation conjunction (i.e., a red vertical in green vertical and red horizontal lines) was much more efficient even when both targets were equally difficult to identify. Using the guided search model, Wolfe et al. explained their data by specifying that at any one time only one value from the first parallel stage of processing can be passed to the serial stage (or attentional level of pro- cessing) for each feature type-that is, only one color and only one orientation value.

Another limitation is that performance on some tasks with pop-out targets is affected if attention is allocated elsewhere. Joseph, Chun, and Nakayama (1997) tested whether removal of attention from a feature search would affect that search. If the search were automatic, it would be expected that search would be just as efficient without attention. Joseph et al. used an RSVP task to report a white letter prior to a visual search for orientation. However, at short intervals between the appearance of the white letter and the visual search screen, there was considerable decrement in search reaction time (RT). Assuming that the appearance of the first screen resulted in some allocation of attention to the white letter, it appeared that this loss of attention was critical, even though the detection was of so-called preattentive features.

A similar finding resulted from a study on the effects of precuing on targets that were defined by color, luminance, or line orientation (Cheal, Lyon, \& Gottlob, 1994). If perceptual responses to these types of targets were truly automatic and attention was not needed, it should not matter whether attention was cued elsewhere. However, in experiments with SEPs in which the task was identification of color, luminance, or line orientation targets, there was a decrement on invalid trials in comparison with valid trials, similar to that found with targets that do not pop out (Cheal et al., 1994). These data suggest that responses to stimuli that may pop out in a visual search task (those said to be found preattentively) may benefit from attention in other tasks. Thus, the automaticity of responses to these types of stimuli (Kahneman \& Treisman, 1984) comes into question.

\section{Identification Part of Task}

In the paradigm used to study MEPs, the success of the search was determined by the performance in the second component of the task (accuracy of target orientation identification). Thus, the dependent measure was not the speed of the response. However, when SOA was varied, the time course for accuracy as a function of SOA provided an indication of the time needed for the search. The second component of the task, identification of the target, did not vary with different conditions. In each case, the same target choices were available; the observer had to indicate one of four possible orientations. Thus, any differences in overall accuracy or in the slope of the accuracy-SOA function would reflect efficiency of attention allocation.

\section{Stimulus-Driven or Goal-Directed Selection}

The present research bears on two questions. The first deals with how responses following various precue types differ. The second is whether advance knowledge of the precue type improves efficiency of attention allocation. In recent theories of visual search, a distinction has been made between contributions from the characters in the 
task (bottom-up, or stimulus-driven, contributions) and those from intentions of the observer (top-down, or goaldirected, contributions). Some research has suggested that only bottom-up factors are useful with a feature search and that top-down selectivity is not possible (Theeuwes, 1991, 1992). Theeuwes (1994) found that attention appeared to be captured by the most salient singleton. Theeuwes (1994) concluded that search for color could be slowed by an irrelevant abrupt onset, and search for an abrupt onset could be slowed by an irrelevant color. In contrast, others have inferred that the ability of feature targets to draw attention is contingent on the attentional set of the observer; in other words, on top-down factors (Folk, Remington, \& Johnston, 1992; Folk, Remington, \& Wright, 1994).

Other researchers have concluded that both bottom-up and top-down aspects of the task contribute to efficient search (Cave \& Wolfe, 1990; Todd \& Kramer, 1994; Wolfe et al., 1989). It has been shown that observers must adopt a singleton-detection search strategy, and that goaldirected attributes can override the stimulus-driven aspects in particular circumstances (Bacon \& Egeth, 1994; Yantis, 1993). Yantis suggested that in the Posnerian light-increment detection paradigm, the singleton precue captures attention because the observer is looking for a singleton target and both cue and target are sudden onsets. However, that does not explain how a singleton sudden-onset precue in an identification task can improve performance when multiple characters (not singleton sudden onsets) are presented on the target screen (Chastain \& Cheal, in press; Cheal et al., 1994; Cheal, Lyon, \& Hubbard, 1991).

\section{Rationale for Present Experiments}

In the research reported in Chastain and Cheal (in press), each precue type was always presented in a separate block so that the observers always knew which type of precue to find. To be certain that they did not have to search for the precue as an odd-man-out, a reminder of the precue was shown at the beginning of each trial.

The question then arises as to whether the same effects would be found if the observer did not know the specific singleton and had to search for one of several unique singletons. It is possible that advance knowledge would have no effect because visual search for a color can be made by parallel processes even when the color is varied from trial to trial, such as when the target is either red in green distractors or green in red distractors (Cheal \& Lyon, 1992a).

A major issue becomes whether, for example, it is as easy to allocate attention to any unique feature as to one particular feature. Thus, in the first experiment, four different types of stationary MEPs (blue in red elements, red in blue elements, vertical in horizontal elements, and horizontal in vertical elements) were used. These were tested in blocked conditions, as in the previous work, but also in mixed conditions. No precue reminder was used, so that in mixed conditions the observer did not know which precue would appear and only general top-down contributions ("look for a singleton") were available. In each case, the task was to report the orientation of the target character that was in the cued location. If the unique feature of the precue requires only bottom-up information, there should be no difference in accuracy between the mixed and blocked conditions. But if top-down information is helpful, performance should be better in the blocked than in the mixed condition.

In Experiment 2, four precues with different features (defined by brightness, color, density of features within the character, and line orientation) appeared in mixed and blocked conditions to determine the effects when there was no overlap in the characteristics of the different precue types. This was of interest for two reasons.

First, in Experiment 1, when the precue and distractors varied from trial to trial, a variable mapping (VM; Shiffrin \& Schneider, 1977) could occur in that the relevant color (or orientation) on one trial could become the irrelevant or background color (or orientation) on another (i.e., the unique precue could be red or the distractors could be red). In Experiment 2, only consistent mapping $(\mathrm{CM})$ could occur; there was no overlap in features such that the critical precue feature in one precue type was the distractor in another (i.e., red was always the unique precue and never the distractor). Shiffrin and Schneider found that search was more rapid with CM than with VM. VM in the mixed conditions and CM in the blocked conditions could have accounted for the mixed-blocked difference in Experiment 1.

Second, within-dimension processing (such as color $\times$ color) may be different from between-dimension processing (such as color $\times$ orientation). In conjunction searches, it has been found that a cross-dimension search (conjunction of color $\times$ orientation) was much more efficient than a within-dimension search (color $\times$ color or orientation $\times$ orientation; Wolfe et al., 1990).

All precues used to this point have been what might be called static precues (Folk et al., 1992; Folk et al., 1994); that is, the critical precue element was defined as a stationary character that differed from other characters on the screen by a static discontinuity such as color. However, it is not known whether a critical precue element that was defined by motion or another dynamic feature that made it a dynamic discontinuity would elicit attention so that there was no difference between mixed and blocked conditions. In Experiment 3, two static MEP precues (blue in red elements and red in blue elements) and two moving MEP precues (a thick horizontal line with vertical movement in stationary thick horizontal lines and a thick vertical line with horizontal movement in stationary thick vertical lines) were tested in mixed and blocked conditions. In Experiment 4, static and dynamic SEP and MEP conditions were contrasted, and in Exper- 
iment 5, differences in precue type defined by line orientation, movement, or both line orientation and movement were compared.

In these experiments, all conditions were controlled so that the identification of the target could not be made on the basis of the "set" for the precue type. All targets were a form of a C, normally oriented or rotated. In contrast, precues were defined by color, line orientation, abrupt onset, or motion. A set was established by full knowledge of which precue type would appear (in blocked trials); for no specific set, precue types within trials were randomly mixed.

\section{EXPERIMENT 1}

For this experiment, all precues were MEPs that were defined by a stationary property-color or line orientation. All targets had to be identified by differences in form - the position of a gap in a $C$. Thus, the property that defined the precue could not be used to identify the target. Also the targets were not single abrupt-onset characters. When the target screen appeared, there was a $\mathrm{C}$ at each possible target location. Each observer was tested on both mixed and blocked trials of each type of precue. No difference between mixed and blocked conditions would suggest that bottom-up contributions of the precue call attention. In contrast, a decrement in the mixed condition compared with the blocked condition would suggest that advance knowledge of the precue type allowed more rapid search for the precue.

\section{Method}

Apparatus. Stimuli for all of these experiments were presented on a Zenith ZCM-1490-Z analogue display controlled by an IBM
PS/2 Model 30. The decay rate of the P-22 phosphor on the display was to $10 \%$ within $1 \mathrm{msec}$. Distance of the observers' eyes from the display was maintained at approximately $38 \mathrm{~cm}$ by a Gulf and Western table-mounted chinrest with head restraint.

Observers. Sixteen observers ( 6 men and 10 women, mean age 23.0 years) were drawn from the introductory psychology subject pool at Boise State University and received extra credit for their participation in a single session of approximately $1 \mathrm{~h}$. In all of these experiments, data from any observer who could not obtain betterthan-chance accuracy were not used and that observer was replaced. Each observer reported normal or corrected-to-normal acuity. Eye movements were monitored continuously during each trial by the experimenter with a tripod-mounted box camera connected to a television set. If an eye movement was observed immediately before, during, or immediately after the exposure, the observer was admonished by the experimenter. However, eye movement was detected on less than $1 \%$ of all trials in each experiment.

Stimuli. There were four possible precue displays (Figure 1), each of which was an MEP and contained seven thick lines $\left(0.3^{\circ}\right.$ $\left.\times 1.2^{\circ}\right)$ that were identical to one another and one that was different from the others. For one condition (blue), seven thick lines were red (IBM color 4), and the unique line was blue (IBM color 9). All were aligned horizontally. For another condition (red), seven thick lines were blue and the unique line was red, and all symbols were aligned vertically. For the third and fourth conditions, all thick lines were white (IBM color 7 on dark-gray background), but there could be either seven thick horizontal lines and one vertical or seven thick vertical lines and one horizontal. The thick lines were arranged in eight locations equally spaced every $45^{\circ}$ (over $3^{\circ}$ of visual angle apart), around the circumference of an imaginary circle, $4.25^{\circ}$ from fixation, with locations at $0^{\circ}, 45^{\circ}, 90^{\circ}, 135^{\circ}$, $180^{\circ}, 225^{\circ}, 270^{\circ}$, and $315^{\circ}$ (the uppermost point of the imaginary circle was considered to be $0^{\circ}$ ).

The target display contained eight white $\mathrm{Cs}\left(\mathrm{cd} / \mathrm{m}^{2}=68.3\right)$, with the direction of the gap in each $\mathrm{C}$ being up, down, left, or right (Figure 2). A complete circle the same size as a $\mathrm{C}$ subtended a visual angle of approximately $0.8^{\circ}$. One $\mathrm{C}$ appeared every $45^{\circ}$ in locations approximately $1^{\circ}$ peripheral to the corresponding precue location. The target was the $C$ at the location near the actual precue.

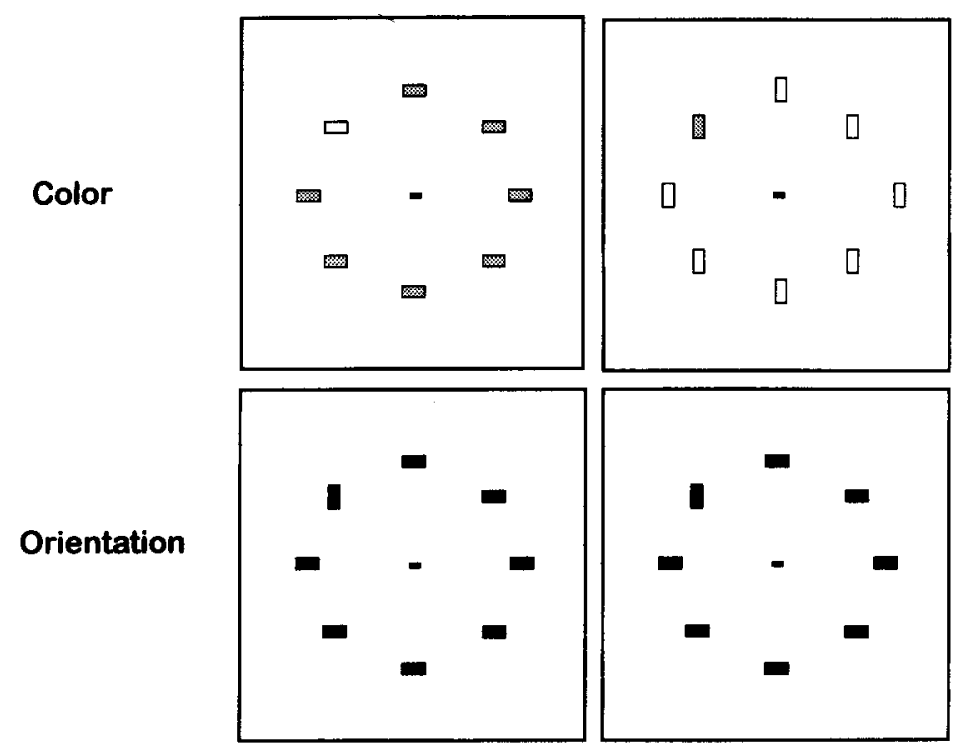

Figure 1. Precue screens for Experiment 1. The unique character could be defined by color - a blue thick line (white in figure) or a red thick line (gray in figure); or by orientation-a vertical or horizontal white thick line (black in figure); all presented on a dark-gray background. 


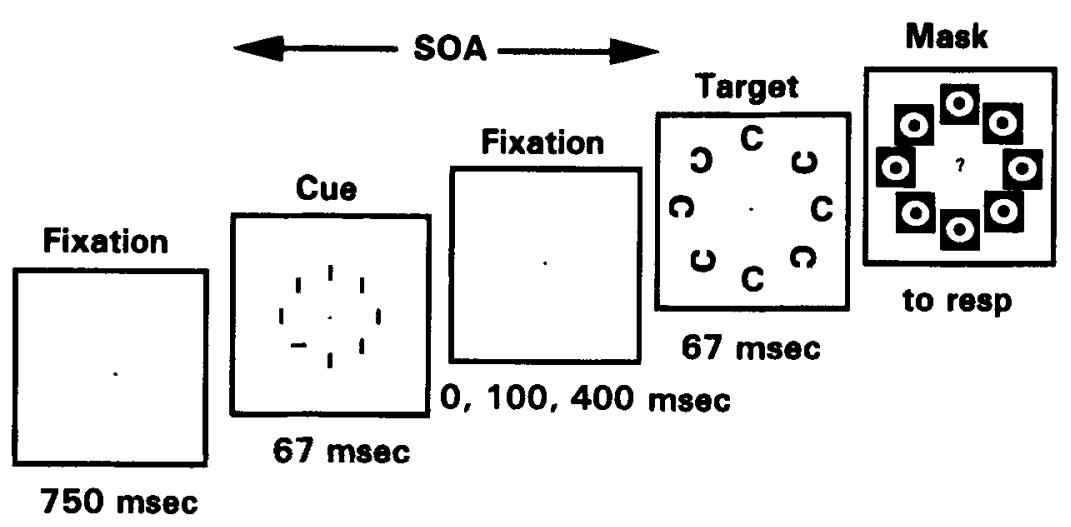

\begin{abstract}
Figure 2. Successive screens for a single trial in Experiment 1. The target location is indicated by the location of the unique character on the precue screen. On this trial, a correct response would be "up," which is the orientation of the $C$ in the cued location. SOA, stimulus onset asynchrony.
\end{abstract}

That is, the unique precue was always valid, and it appeared at each of the eight locations equally often. The gap in the precued $\mathrm{C}$ (the target) was equally likely to be in each of the four positions, whereas positions of the gaps in the uncued Cs were selected at random. A white postexposure mask, present at each of the target locations, was an outline of a complete circle.

Experimental Design. Each observer received 64 practice trials (all conditions randomized) at the beginning of the experiment. The responses for these trials were not recorded. For the experimental trials, the four precue types were each presented twice to each observer-one condition in which all four precue types were mixed randomly and one condition in which there were separate blocks for each precue type. Before each block in the blocked condition, observers received 10 practice trials for that precue type. Before the mixed condition, observers received 40 practice trials, 10 for each precue type, with the order randomized. These practice trial responses also were not recorded. Order of presentation (blocked trials or mixed trials first) was evenly balanced across observers. Each condition (blocked and mixed trials) consisted of the factorial combination of two replications of four precue conditions, eight locations $\times$ three SOAs $(67,167$, or $467 \mathrm{msec})$, which resulted in a total of 192 experimental trials, with variable combinations presented in a different random order to each observer. Order of precue conditions for the blocked conditions was counterbalanced via a digram-balanced Latin square.

Procedure. At the beginning of each trial, there was a fixation dot in the center of the screen for $750 \mathrm{msec}$ (Figure 2). No precue reminder was used at the start of each trial so that the precue type would be a surprise when it appeared in the mixed-trial condition. The display that contained the precue followed the fixation dot and remained in view for four screen refreshes $(67 \mathrm{msec})$. After the SOA, the target display appeared for $67 \mathrm{msec}$. The observer pressed one of the four arrow keys on the numeric keypad to indicate the direction of the gap in the $\mathrm{C}$ in the precued location. A "happy face" then appeared if the response was correct, or a minus sign if it was incorrect, for $1 \mathrm{sec}$. The next trial began approximately $2 \mathrm{sec}$ later. The observer could pause at any time merely by withholding the response until ready.

Data Analyses. A hi-log linear analysis for dichotomous data was computed first on all data. This was followed by separate analyses of individual data and comparisons with the Wilcoxon signed ranks test.

\section{Results and Discussion}

Because there were no significant interactions, the data were collapsed over mixed/blocked conditions (Fig- ure 3) and over SOAs (Figure 4). There was a significant increase in accuracy with increasing SOA $\left[\chi^{2}(2)=89.22\right.$, $p<.0001]$ and significant differences among the four precue types $\left[\chi^{2}(3)=49.40, p<.0001\right]$; also, the blocked condition resulted in higher accuracy than the mixed condition $\left[\chi^{2}(1)=15.04, p<.0001\right]$.

Mixed versus blocked conditions. Mixing the four types of stationary precues within blocks in the location-cuing task resulted in much poorer accuracy than when they were presented in separate blocks and the observers knew which precue type would appear. Because the hi-log linear analysis is based on a chi-square analysis, it was important to examine data for each individual observer separately. For 10 observers, blocked was better than mixed; for 3 observers, there was no difference between mixed and blocked; and for another 3 observers, mixed was slightly better than blocked (all 6 of the latter were tested with the blocked condition first). A significant difference was shown with a Wilcoxon signed ranks test $[T(15)=$

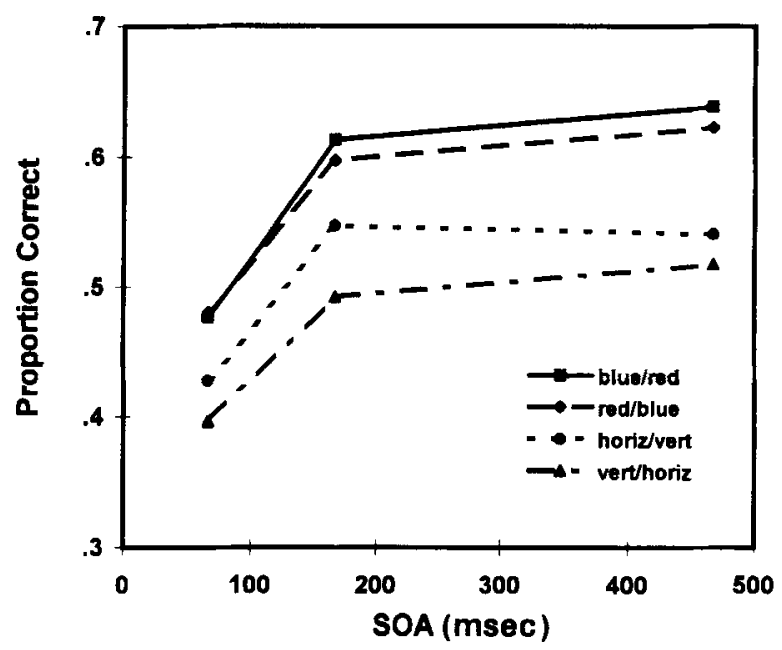

Figure 3. Proportion correct as a function of the stimulus onset asynchrony (SOA, in milliseconds) between the onset of the precue and the onset of the target for the four precue types in Experiment 1. 


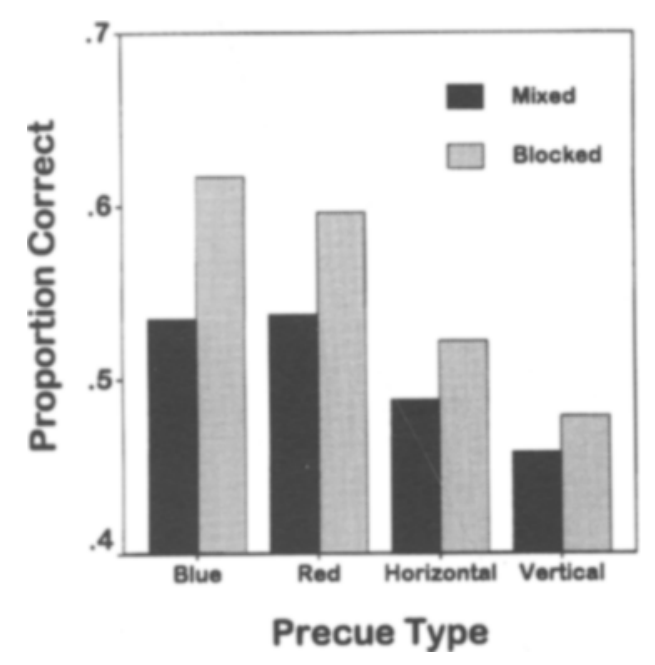

Figure 4. Proportion correct as a function of the four precue types for mixed and blocked presentation in Experiment 1.

$10, p<.01]$, which supports the conclusion that blocking these precue types results in higher accuracy than mixing them randomly.

It is obvious from the data in Figure 4 that the unique character on the precue screen did not attract attention as readily as when the observer had advance knowledge of what character would be the actual precue. These data are consistent with research in which RTs were faster when the exact target stimulus was known (Theeuwes, 1991, 1992; Treisman, 1988) or all targets were in the same dimension (Müller, Heller, \& Ziegler, 1995). Thus, although observers can use an unknown unique character relatively well, they cannot use it as well as they can with advance knowledge. Note that none of the precue types was related to the type of response that had to be made to the target; in each case the response was the identification of the position of a gap in a C - recognition of the shape of the character in the cued location.

Differences among precue types. To further understand the differences among the four cue types, another experiment was conducted in which 24 observers were shown 48 trials of each precue type (order counterbalanced across observers), but no target was presented. The method was similar to that of Experiment 2 of Chastain and Cheal (in press), except that eight characters were used in the display. The observers were instructed to respond with the location that was precued as quickly as possible. The precue types differed significantly $[F(3)=$ $26.73, p<.001]$. Interestingly, there was an inverse relationship between accuracy in the location-cuing experiment and latency to respond to the cued location (blue in red $=421.7 \mathrm{msec}$, red in blue $=413.4 \mathrm{msec}$, horizontal in verticals $=460.4 \mathrm{msec}$, and vertical in horizontals $=$ 458.9 msec compared with either 167 - or $467-\mathrm{msec}$ accuracy in Figure 3). Errors were less than 3\% for each precue and did not differ significantly. Thus, at least some of the differences in accuracy were due to the difference in time needed to move attention to the cued location. This will be discussed further below.

Differences between color and orientation precues. In separate analyses in which the two color precue types were combined and the two line orientation precue types were combined, it was shown that (1) color precues resulted in higher accuracy than orientation precues (horizontal/vertical) $\left[\chi^{2}(1)=44.32, p<.0001\right]$ and (2) again, blocked trials yielded higher accuracy than mixed trials $\left[\chi^{2}(1)=14.81, p<.0001\right]$. Note that there was no dropoff in accuracy at the longest SOA, consistent with previous data with MEPs (Chastain \& Cheal, in press).

Another possible influence on these data is the type of precue on the preceding trial (Maljkovic \& Nakayama, 1994). To determine whether the sequence of precues affected performance, a sequential analysis was made in which an interaction was examined among the four possible precues and whether the precue on trial $n$ matched the precue on trial $n-1$ or not. This was not significant $\left[\chi^{2}(3)=0.87, p=.83\right]$. A similar analysis was computed using the cue type (color or orientation), with similar results $\left[\chi^{2}(1)=0.16, p=.69\right]$. Thus, there is no evidence that the sequence of precues across trials affected performance. These results are not too surprising considering that in this experiment a target screen and mask followed each cue screen. This distraction results in a very different task from the one used by Maljkovic and Nakayama. In their task, there were no intervening stimuli between trials.

\section{EXPERIMENT 2}

It is clear from Experiment 1 that with these stationary precues, it is beneficial to know in advance (by blocking of precue type) which precue will appear. Would this also be true if the mapping of precue type were always consistent (any unique precue could not also be a distractor) and four distinct types of precues were used rather than precue types with some overlapping features, as were used in Experiment 1 ?

Müller et al. (1995) demonstrated that although both within- and across-dimension visual searches have flat search functions, responses are slower when they are across dimensions. Also, Wolfe et al. (1990) found that search for conjunctions with two of the same features was slower than search for conjunctions between two features. It is possible that four different features (color, orientation, brightness, and density) would benefit less from blocking than what was found in Experiment 1, with only two different features (color and orientation).

\section{Method}

The method was the same as that of Experiment 1 with the exception of the precues. Each type was defined by a different characteristic-brightness, color, density, or orientation. (1) For brightness differences, all eight characters were lines slanted to the right $\left(1.2^{\circ} \times 0.3^{\circ}\right)$, one bright and the other seven dim. (2) For color difference, a single red rectangle $\left(0.5^{\circ} \times 0.6^{\circ}\right)$ appeared with seven blue rectangles. (3) For density differences, one character was an 
$8 \times 10$ pixel outline of a thick line $\left(1.1^{\circ} \times 0.9^{\circ}\right)$ with the center $4 \times$ 6 pixels turned off $\left(0.6^{\circ} \times 0.3^{\circ}\right)$. The other seven characters were composed of a grid of $3 \times 3$ horizontal and vertical lines, which left six openings of $2 \times 2$ pixels; overall luminance was the same for the two characters. (4) For line orientation differences, one character was a vertical line $\left(1.2^{\circ} \times 0.3^{\circ}\right)$ and seven characters were horizontal lines $\left(1.1^{\circ} \times 0.3^{\circ}\right)$. Precues were presented for $67 \mathrm{msec}$, and there were three SOAs $(67,167$, and $467 \mathrm{msec})$.

There were 16 observers ( 4 men and 12 women, mean age 21.5 years); 8 received the blocked condition first and 8 received the mixed condition first.

\section{Results and Discussion}

Mixed versus blocked conditions. The most interesting result of this experiment was that, again, observers performed more accurately when the different precue types were presented in separate blocks than when they were presented in randomly mixed blocks $\left[\chi^{2}(1)=12.88\right.$, $p<.001$; Figure 5]. Twelve of the 16 observers did better on the blocked than on the mixed conditions; the 4 who did not were tested on blocked first and, thus, their accuracy improved sufficiently by the time they were presented with the mixed set to offset the blocked advantage.

The occurrence of four possible features in the trials did not result in more decrement in the mixed condition compared with the blocked condition than the two possible features in Experiment 1. In fact, differences were very similar. In Experiment 1, the two color conditions resulted in a difference of .07 between mixed and blocked conditions; in Experiment 2, the difference was .08. There was even less difference between experiments for line orientation. There was .03 difference between mixed and blocked conditions in each experiment.

The differences between mixed and blocked conditions in these two experiments are consistent with those found by Müller et al. (1995), and it is possible to derive an RT measure from our data by looking at the SOA needed to reach a particular proportion of correct responses. It might seem possible, therefore, to compare the data from our work with the Müller et al. data. ${ }^{1}$ However, the RTs are not comparable because RT in visual search includes the time needed to make the motor response as well as the time needed to determine the presence or location of the stimulus.

Differences among precue types. There was a significant effect of precue type, also illustrated in Figure 5 $\left[\chi^{2}(3)=63.37, p<.0001\right]$. Color and density precues produced nearly equal accuracy $(M \mathrm{~s}=.54, .53)$, brightness produced somewhat poorer accuracy $(M=.51)$, and line orientation produced the poorest accuracy $(M=.41)$.

Another 24 observers were given the location RT task and again the precue types differed significantly $[F(3)=$ $9.54, p<.001]$. Also, there was an inverse relationship between latency to respond to the location and accuracy in the location-cuing task, similar to that in Experiment 1 (color $=411.7 \mathrm{msec}$, density $=439.8 \mathrm{msec}$, brightness $=$ $420.7 \mathrm{msec}$, and line orientation $=478.0 \mathrm{msec}$ ). Errors

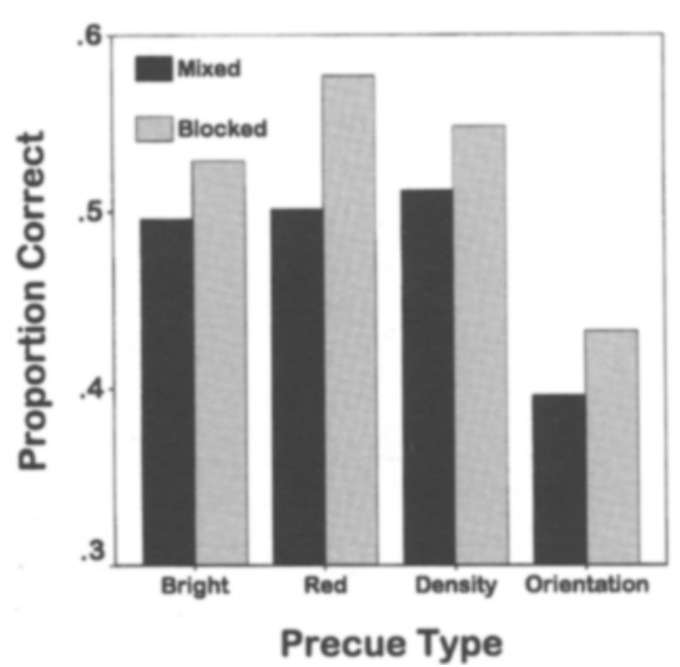

Figure 5. Proportion correct as a function of the four precue types for mixed and blocked presentation in Experiment 2 .

were less than $4 \%$ for each precue type and did not differ significantly.

Because of the similar results on the negative relationship between latency and accuracy in Experiments 1 and 2, the data from the eight precue types were combined along with latency and accuracy measures for responding to a single vertical line precue (an SEP; from an unpublished experiment). As can be seen in Figure 6, there was a strong negative correlation between accuracy and latency $[r(7)=-.846]$.

Our data do not imply that all accuracy of identification following static precues would be the result of the latency to determine the location of the precue. Too few precue types were used here to make that determination. In research in which performance in visual search and location cuing were compared, performance was quite similar in the two paradigms for color and line orientation targets, but not for targets that differed in number of terminators (Cheal \& Lyon, 1994). If additional precue types had been used, the conclusions might differ, but only future research will allow that determination to be made.

Accuracy improved with increasing SOA for 15 of the 16 observers $\left[\chi^{2}(2)=82.98, p<.0001\right]$. The only significant interaction was SOA $\times$ precue type $\left[\chi^{2}(6)=\right.$ $32.57, p<.0001]$. This interaction resulted because mean accuracy for brightness and density peaked at $167 \mathrm{msec}$, but for color and orientation, peak accuracy came at the longest SOA, as it did in Experiment 1.

Differences between color and line orientation precues. It is quite interesting to note that in these two experiments the mean accuracy responses for line orientation precues was considerably lower than for color precues (Figures 4 and 5). This may be because color is more salient than line orientation. Folk et al. (1994) concluded 


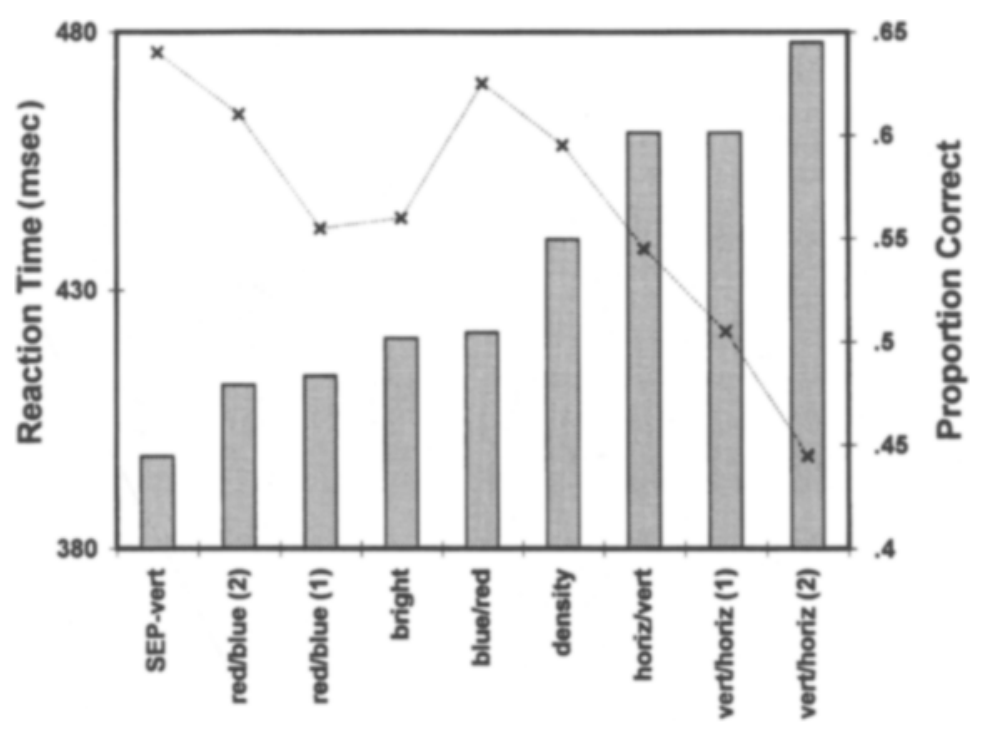

Figure 6. Plot of reaction time in milliseconds to respond with the location of a precue (bars) and of proportion correct in the location-cuing task in Experiments 1 and 2 (Xs connected with dotted line) for nine precues. Note the inverse relationship.

that salience was partly responsible for differences in their paradigm also. This difference between color precues and line orientation precues would not have been predicted from the earlier research of Cheal et al. (1994). The amount of improvement with SOA in the locationcuing paradigm is about the same for identification of color and line orientation targets (Cheal \& Lyon, 1992b), which suggests the same need for attention resources. However, differences in the same direction as the present results were found in RT for search for color and line orientation conjunctions (Wolfe et al., 1990).

The difference in accuracy between color precues and line orientation precues suggests an explanation for the difference between the results of Chastain and Cheal (in press) and those of Chastain (1996). In Chastain and Cheal, a color-defined MEP resulted in a slower rise in accuracy than shown by an SEP, but not as slow as when a central precue was used. In contrast, Chastain found that line orientation MEPs resulted in data very similar to those collected with a central precue. The reason for this difference between color or luminance MEPs and orientation MEPs is not clear. It is possible that the differences seen at short SOAs in this paradigm reflect the differences in saliency of the precue, as shown here and in Wolfe et al. (1990), where identification of an orientation $\times$ orientation conjunction was slower than identification of a color $\times$ color conjunction. Also, it was shown that color distractors interfered with form discrimination, but form distractors did not interfere with color discrimination even when the exact features were known (Theeuwes, 1991, 1992).

It should be noted, however, that although there was some discrepancy between the rise time between color or luminance MEPs and line orientation MEPs, there was no discrepancy in the data for long SOAs; in all cases there was no decline in accuracy at long SOAs. Thus, this feature of static MEP data suggests that, as with a central precue, a voluntary allocation of attention is necessary for the precue to be useful.

\section{EXPERIMENT 3}

In Experiments 1 and 2, only static precues were used; that is, once the screen was drawn, there was no movement in the characters. In this experiment, static MEP precues were compared with dynamic MEP precues. The dynamic precues were defined by apparent motion. Again, all conditions, including mixed and blocked trials, were given to each observer.

If an attentional set is selective either to static or dynamic properties, it may not be possible to be selective to both simultaneously. In that case, mixing these precue types would have an adverse effect on performance with both static and dynamic precues.

\section{Method}

The method was much the same as that of Experiments 1 and 2 . The principal difference was in the four precue screens (Figure 7). Two were stationary precue types all with thick horizontal lines; there were seven red thick lines and one blue thick line for one, and the other was a single red thick line and seven blue thick lines. There were also two moving precue types: Each had eight thick lines all oriented either horizontally or all oriented vertically. The important aspect of the motion precues was that one of the thick lines flashed on for $33 \mathrm{msec}$ at one location and then for $33 \mathrm{msec}$ at an adjacent location and then reversed, so that there was apparent back-and-forth movement. In one condition, the thick lines were horizontal with up and down apparent motion; in the other condition, the thick lines were oriented vertically with side-to-side apparent motion. To provide the apparent motion, it was necessary 


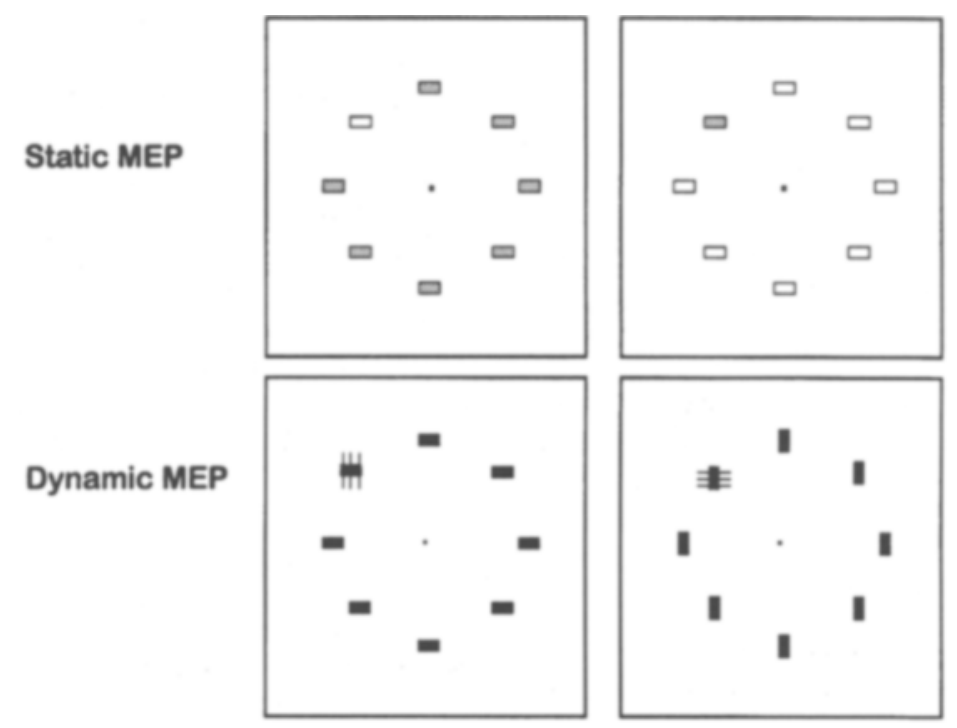

Figure 7. Precue screens for Experiment 3. The static multiple-element precues (MEPs) could be blue (white in figure) or red (gray in figure); the dynamic MEPs were defined by apparent motion vertically for white horizontal thick lines (black in figure) and horizontally for white vertical thick lines; all presented on dark-gray background.

to flash the precue four times for $33 \mathrm{msec}$ each. Thus, there were $133 \mathrm{msec}$ for precue presentation, after which the target screen followed immediately (only one $\mathrm{SOA}=133 \mathrm{msec}$ ).

There were 16 observers ( 3 men and 13 women, mean age 26.2 years); 8 received the blocked condition first and 8 received the mixed condition first.

\section{Results and Discussion}

Stationary precues: Mixed versus blocked conditions. Blocked trials resulted in higher accuracy than mixed trials $\left[\chi^{2}(1)=39.43, p<.0001\right]$. Eleven of 16 observers had higher accuracy on blocked trials than on mixed $[T(15)=17.5, p<.02]$. Thus, the difference between blocked and mixed trials replicated that found in Experiment 1 . Color (red or blue) and mixed/blocked conditions did not interact $\left[\chi^{2}(1)=2.69, p>.10\right]$.

Stationary precues: Differences in precue types. The results with stationary precues paralleled those in Experiment 1: Red precues produced higher accuracy than blue precues $\left[\chi^{2}(1)=15.54, p<.0001\right]$ according to the hi-log linear analysis. However, only half of the 16 observers had higher accuracy on red than blue, which was not significant according to the Wilcoxon signed rank test $[T(15)=$ $38.5, p>.10]$.

Moving precues. The data with moving precues were quite different: There was no significant effect of vertical versus horizontal precues $\left[\chi^{2}(1)=2.59, p>.10\right]$, of mixed versus blocked conditions $\left[\chi^{2}(1)=0.23, p>.10\right]$, or any interaction between the two $\left[\chi^{2}(1)=0.40, p>.90\right]$.

Moving versus stationary precues. Because there were no differences between the two moving precues and the differences between red and blue were in the same direction (although not as strong) as those in Experi- ment 1, the data were collapsed (Figure 8) across the two precues for each type. The overall analysis of these data revealed much higher accuracy for moving precues than for stationary precues $\left[\chi^{2}(1)=145.02, p<.0001\right]$, higher accuracy for blocked than for mixed trials $\left[\chi^{2}(1)=24.46\right.$, $p<.0001]$, and a significant interaction that shows that the stationary precues were solely responsible for the mixed versus blocked effect $\left[\chi^{2}(1)=14.79, p<.0001\right]$.

Thus, a dynamic MEP is more efficient at calling attention than is a static MEP. Further, mixing static and dynamic MEPs did not adversely affect performance with the latter, nor did it adversely affect performance with static precues more than mixing them with other static precues.

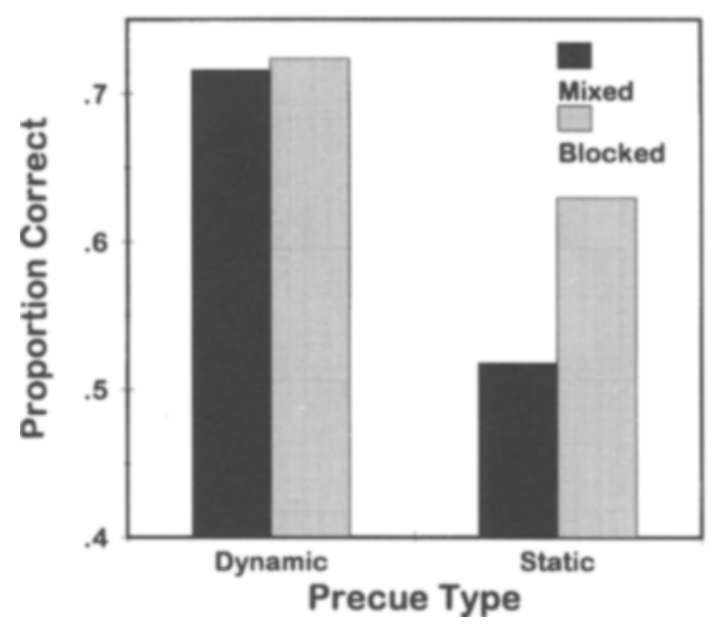

Figure 8. Proportion correct as a function of dynamic or static precue types for mixed and blocked presentation in Experiment 3. 


\section{EXPERIMENT 4}

In the present experiment, stationary and moving SEP and MEP conditions were contrasted, again in mixed and blocked conditions. This experiment added an interesting dimension to the results of Experiment 3. An SEP can be considered to be a dynamic discontinuity because it consists of a single abrupt-onset character. Thus, we can compare the effects of the abrupt onset with the effects of an SEP that has both the dynamic discontinuity of abrupt onset and the added dynamic discontinuity of apparent motion. Again, these are within-observer manipulations with both mixed and blocked conditions.

\section{Method}

There were again four precue types: Two were SEPs and two were MEPs. One SEP and one MEP were stationary precues (in that they did not move once presented, although the SEP was a single sudden onset), and the other SEP and the other MEP were moving precues with translational movement of the actual precue (Figure 9). In all four types of precues, the actual precue was a thick vertical line. In both MEPs, the seven additional characters were thick horizontal lines. All lines were white on a dark-gray background. In the dynamic conditions, the actual precue was presented as in Experiment 2 in order to produce apparent motion. Thus, there was only one SOA $(133 \mathrm{msec})$. There were $16 \mathrm{ob}-$ servers ( 10 men and 6 women, mean age 21.9 years); half of them received the mixed condition first and half received the blocked condition first.

\section{Results and Discussion}

Mixed versus blocked conditions. Means for the eight different conditions are presented in Figure 10. There was no significant effect of mixed versus blocked for moving precues $\left[\chi^{2}(1)=1.83, p>.10\right]$ or for stationary precues $\left[\chi^{2}(1)=2.64, p>.10\right]$ in separate analyses.

Differences in precue types. Separate analyses for each precue type showed that there were no significant differences between the two moving precues $\left[\chi^{2}(1)=1.57, p>\right.$ .10 ], but for stationary precues, SEP was better than MEP $\left[\chi^{2}(1)=40.38, p<.0001\right]$. This difference was confirmed with a Wilcoxon signed ranks test; 14 of $16 \mathrm{ob}$ servers showed the effect $[T(15)=16.5, p<.02]$.

In the overall analysis, there were significant interactions between SEP/MEP and moving/stationary precues $\left[X^{2}(1)=28.22, p<.0001\right]$ and between moving/stationary and mixed/blocked $\left[\chi^{2}(1)=4.45, p<.05\right]$, but no three-way interaction. The interaction between precue type (moving/stationary) and blocking condition is of particular interest because the differences for stationary precues were in the same direction as that found in Experiment 2 (accuracy was higher for blocked condition than for mixed condition). The interaction was shown in that 9 of 16 observers were better on mixed than blocked for moving SEP and for moving MEP, whereas for stationary MEP and for stationary SEP, 9 or 10 of 16 observers were better on blocked conditions than on mixed.

The significant interactions provide evidence that the SEP-MEP difference occurs only with stationary precues (also shown in the separate analyses by precue type), and also weak evidence that blocking trials improved performance with stationary precues, but hindered performance with moving precues.

There is little, if any, evidence that the inclusion of both sudden onset and apparent motion benefit an SEP over an SEP with only sudden onset. Any difference in

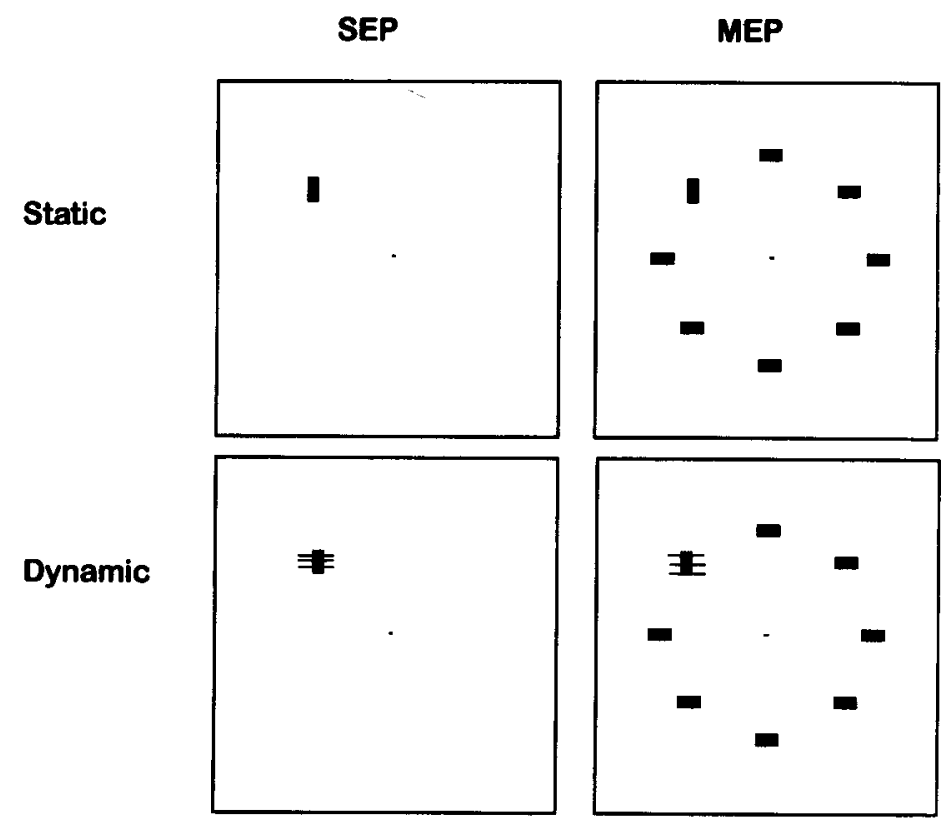

Figure 9. Precue screens for Experiment 4. All precues were vertical thick lines, which were either static or dynamic (defined by apparent horizontal motion). SEP, single-element precue; MEP, multiple-element precue. 


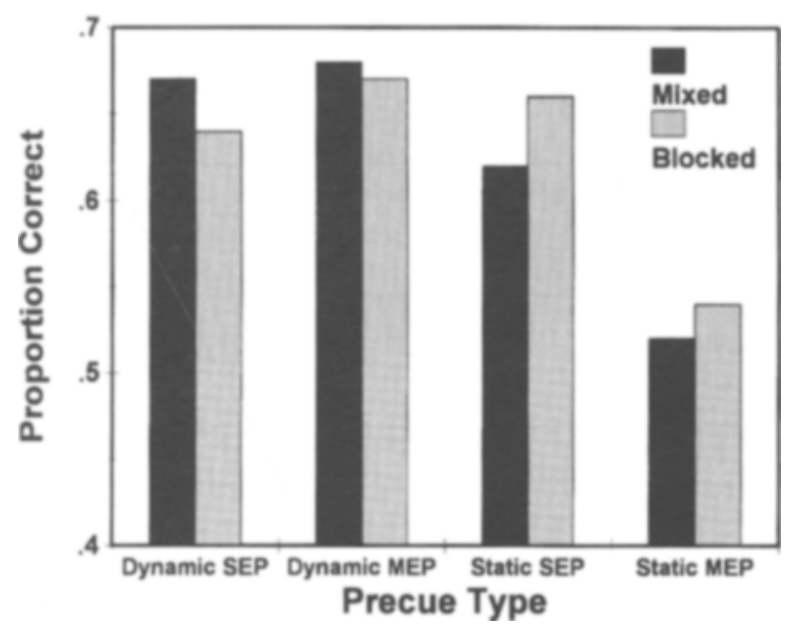

Figure 10. Proportion correct as a function of the four precue types for mixed and blocked presentation in Experiment 4. MEP, multipleelement precue; SEP, single-element precue.

these conditions was small, and for the blocked conditions, the difference was actually in the opposite direction.

\section{EXPERIMENT 5}

A question remained as to relative differences between precues that are defined only by movement and those that are defined by both movement and orientation. In this experiment, these two types of precues were contrasted with a stationary MEP defined only by orientation, again in mixed and blocked conditions. Thus, precues were defined by orientation, by movement, or by both.

\section{Method}

There were three precue types; all were MEPs. One MEP was stationary (in that it did not move once presented) and the other MEPs were moving precues with translational apparent movement of the actual precue (Figure 11). In the two types of precues with orientation differences, the actual precue was a thick vertical line (approximately $1^{\circ}$ in length). In the MEP without orientation differences, the actual precue was a thick horizontal line (also $1^{\circ}$ in length). In each condition, the seven additional characters were thick horizontal lines. All lines were white on a dark-gray background. In the dynamic conditions, the actual precue was presented as in Experiment 2 in order to produce apparent motion (a single 133-msec SOA).

There were 36 observers ( 18 men and 18 women, mean age 21.4 years); all were first presented with 64 practice trials; then half of them received 192 trials in which the three precue types were mixed and then 192 trials in which the precue types were biocked; the order was reversed for the other half of the observers. The order of presentation of the different precue types in the blocked condition was counterbalanced across observers.

\section{Results and Discussion}

When all data were analyzed together (Figure 12), there were significant effects of precue type $\left[\chi^{2}(2)=\right.$ $830.63, p<.0001]$, of $\mathrm{mix} / \mathrm{block}\left[\chi^{2}(1)=14.84, p<\right.$
$.0001]$, and interactions between mix/block and precue type $\left[\chi^{2}(1)=26.21, p<.0001\right]$.

Mixed versus blocked conditions. In this experiment, when using the stationary precues, observers did better when the precues were mixed than when they were blocked. The effect for stationary precues appears to be robust; 23 of 36 observers did better with the mixed condition than with the blocked condition. Of the other 13 observers, one had the same accuracy for mixed and blocked, and for 11 of the 12 observers who scored better on the blocked condition, the mixed condition was presented first.

Higher accuracy for mixed than blocked with the stationary precues could have been because the two thirds of the trials with moving precues were much easier to do than those with stationary precues. Subjectively, it seemed that when the block of stationary precues appeared, one tended to quit trying because of the difficulty.

Differences in precue types. The effect of precue type was very strong. The dynamic precues resulted in higher accuracy than the static precues. Thus, the stationary MEPs appeared to be less efficient in directing attention than the moving MEPs. The poorest accuracy was obtained with static MEPs; 34 of the 36 observers showed this effect. For just 1 observer, there was no difference among the three precues.

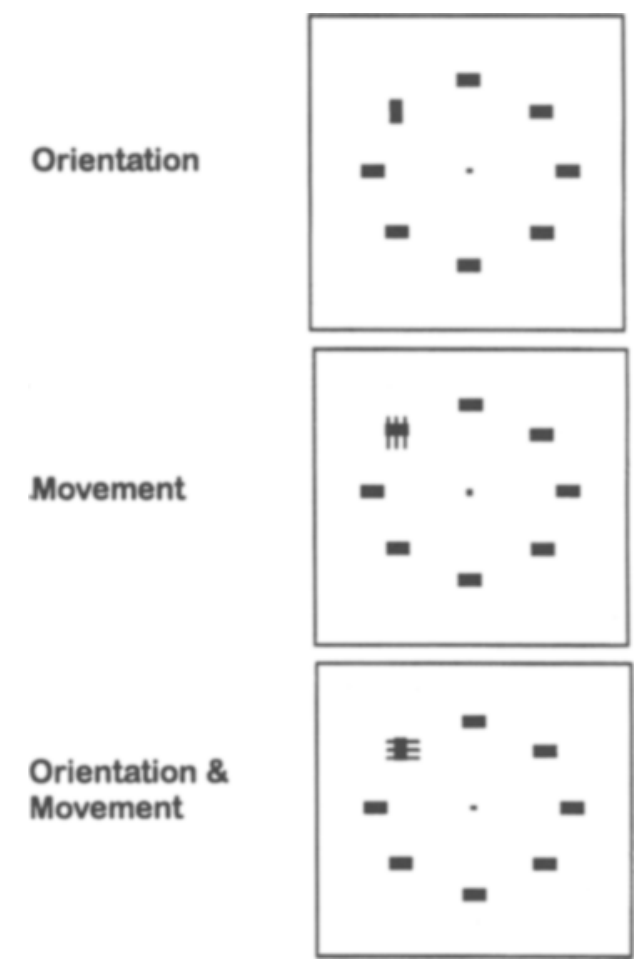

Figure 11. Precue screens for Experiment 5. The actual precue was a vertical thick line that differed in orientation, a horizontal thick line that differed in apparent motion, or a vertical thick line that differed in both orientation and apparent motion. 


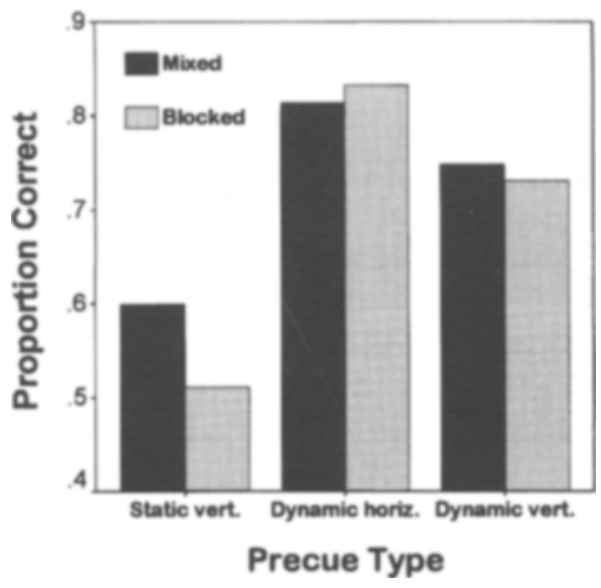

Figure 12. Proportion correct as a function of the three precue types for mixed and blocked presentation in Experiment 5 .

In addition, although both dynamic precues were very efficient, the precue defined only by movement provided better accuracy than that defined by both movement and orientation $\left[\chi^{2}(1)=95.60, p<.0001\right]$. This effect was shown by 30 of the 36 observers. Thus, the inclusion of two sources of information (here, both movement and line orientation) again did not facilitate performance; in fact, performance was hindered.

Another group of 24 observers was tested with four dynamic precues in the location RT task. The comparison between two dynamic precues in Experiment 3 and two in Experiment 5 did not show the inverse relationship between RT and accuracy that was found with static precues in Experiments 1 and 2. There were too few precue types for a formal analysis, but any relationship that occurred between the two measures was in the opposite direction. As latency for locating the cued location increased (vertical/horizontal, 453.6; vertical/vertical, 462.9; horizontal/horizontal 480.3), accuracy in location cuing either did not change or also increased (vertical/horizontal, .70; vertical/vertical, .69; horizontal/horizontal, .78).

\section{GENERAL DISCUSSION}

\section{Static Precues}

Differences between SEPs and MEPs. The differences found between the effects of SEPs and MEPs parallel the differences found by Chastain and Cheal (in press) and support some new conclusions as to their effectiveness. Again, we found that there is no decline in accuracy at long SOAs with static MEPs (Experiment 1; Figure 3), as is often found with static SEPs.

Differences in precue types. Different types of features resulted in different accuracy levels. Searches for color and luminance were more efficient than searches for line orientation. Similarly, RTs were faster in a color-matching task than in a line-matching task (Humphreys \& Boucart, 1997). The differences in the present experiments appear to be largely determined by the time taken to localize the singleton element. This was shown by the strong negative correlation between accuracy of identification following a static precue and latency to indicate the location of the precue. Longer latency to determine the location of the singleton results in less time for attention resources to build at the target location prior to target onset, so that there is poorer performance in identifying the target once it appears.

There seem to be basic differences in our responses to color and orientation. Even though both types of targets can be found by parallel search (Cave \& Wolfe, 1990; Cheal \& Lyon, 1992a; Treisman, 1988), and neither benefit much from time to focus attention in location cuing (Cheal \& Lyon, 1992b), it is clear that they do not function interchangeably in other research. For instance, semantic information affects performance with orientation, but not with color (Humphreys \& Boucart, 1997; Livingston \& Hubel, 1988). Humphreys and Boucart suggested that basic neurophysiological mechanisms may result in attention to color operating on different pathways than attention to form (i.e., including orientation), although each may influence activation of the other.

Mixed versus blocked conditions. When only static precues were used, it was shown that observers were more accurate when the different stationary precues (color, luminance, line orientation, or density) were presented in separate blocks than when they were mixed randomly within blocks (Experiments 1 and 2; Figures 4 and 5). This was also true for stationary precues if there was an equal number of dynamic precues in the same experiment (Figures 8 and 10). Note that in the mixed condition in these experiments, the observers had a set for finding the singleton; otherwise, they could not complete the task. Even so, this set did not compensate for actually knowing what the singleton would be. Thus, adopting a singleton-detection search strategy (Bacon \& Egeth, 1994) is not sufficient to provide the most efficient search in the present paradigm. In these experiments, the set for the target type (which was always the same) was not critical, but the set for the precue type (which was essential for completion of the task) was critical for the best performance.

These results provide an important addition to the visual search literature. In this paradigm, where the search is for a character that will indicate the target location, the unique character is identified not only with the stimulus characteristics (bottom-up information), but also with advanced knowledge of the pertinent characteristics (topdown information), especially in the blocked condition. The use of both bottom-up and top-down information is consistent with guided search theory (Wolfe, 1994; Wolfe et al., 1989) and with data on target identification (Cheal, 1997). In the location-cuing paradigm, a peripheral precue may elicit attention primarily with bottom-up effects, but preknowledge of the target type (a top-down effect) can also affect performance. The latter interac- 
tion of exogenous and endogenous factors has been related to changes in permeability of filters in the concepts of the VAP filters (variable and permeable filters) metaphor for allocation of attention (Cheal, 1997).

\section{Dynamic Precues}

Differences between SEPs and MEPs and precue types. Unlike the static precues, there were few differences between SEPs and MEPs when the precues were determined by apparent motion. There was also little difference between whether the movement was horizontal or vertical. In these experiments, the dynamic precue could be said to be "perfectly informative" (Hillstrom \& Yantis, 1994) in that it indicated the target location, and, thus, would be expected to guide attention.

Mixed versus blocked presentation. In contrast to static precues, there was no advantage for blocking dynamic precues. Observers did just as well when dynamic precues were mixed with another dynamic precue type and with stationary precues (Experiments 3 and 5; Figures 8 and 11) or when dynamic SEPs and dynamic MEPs were mixed, as when they were presented in separate blocks (Experiment 4; Figure 10). For these dynamic precues, some observers may even do better on mixed than blocked conditions on some occasions. One paradoxical result was that when static MEPs were mixed with a larger number of dynamic MEP precues, observers had better accuracy in the mixed condition than in the blocked (Experiment 5; Figure 12). One possible explanation is the relative difficulty of the block with all static trials in comparison with the mixture of static and dynamic MEP trials, which may have resulted in loss of effort in the all-static precue condition.

There was another somewhat paradoxical result. Observers had better accuracy when there was only one source of information as to the actual precue than when there were two sources of information (either sudden onset and apparent motion, as in Experiment 4, or apparent motion and line orientation, as in Experiment 5). Perhaps having a second source of information added a small amount of confusion to the task.

\section{Static Discontinuities and Dynamic Discontinuities}

The present experiments have revealed several differences between precues based on static discontinuities and those based on dynamic discontinuities. (1) The dynamic precues resulted in much more efficient responses, as shown by greater accuracy of identification. (2) With static precues, there was a large advantage in knowing which precues would occur, whereas preknowledge of the precue type was not advantageous with dynamic precues. (3) Although a static SEP results in more efficient allocation of attention than does a static MEP, that is not true with dynamic SEPs and MEPs. (4) There is a negative correlation between accuracy of identification following a static precue and latency to indicate the location of such precues, but that correlation does not appear to exist with dynamic precues. One might think that these differences are because, consistent with Guided Search (Wolfe, 1994), the dynamic precue is so efficient that a bottom-up ceiling effect has been reached and there is no room for any top-down facilitation (see note 1). Although identification accuracy is well below the 1.0 ceiling (Figures 8,10 , and 12), the actual ceiling could be determined by the limitations on the information available from the target during its brief presentation. The efficient search may be because the moving precue segregates a new perceptual object from background elements and guides attention efficiently when it is informative, as it is here (Hillstrom \& Yantis, 1994).

Obviously, a "set" for static precues (or dynamic precues) is not supported by the present data. If it were, a precue should elicit attention only if it were defined by that feature (static or dynamic). If orienting to the MEPs was based on the set for that type of precue, one would expect no mixed-blocked difference between precues that are all static or between static precues that appear with dynamic precues (as in Experiments 3 and 4). This was not what was found.

In Experiments 1 and 2, mixing four types of static precues resulted in a large decrement in accuracy compared with blocking those same precue types. In each case, all eight elements appeared at once on the precue screen, and the critical precue element was defined by luminance, color, density, or line orientation-all features that can be found with parallel search (Cheal \& Lyon, 1992a). For each precue type, mixing the precues resulted in poorer identification accuracy. Thus, responses were not the result of attention elicited by any static singleton. That is, the appearance of a distinct color, luminance, or orientation cannot be said to result in automatic orienting to that feature. This is consistent with data from the location-cuing paradigm: When the same features that were used as precues here define the target, there is a decrement on trials that are cued to the wrong location compared with trials that are correctly cued (Cheal et al., 1991; Cheal et al., 1994). Thus, features that allow targets to be found with parallel search are not completely automatic in eliciting attention.

In Experiments 3 and 4, there was again a decrement with static precues when static and dynamic precues were mixed. In contrast, there was no decrement for dynamic precues when they were mixed with static precues. Thus, different static discontinuities do not serve equally well as precues in the present paradigm. They are not interchangeable, as shown by the poorer accuracy when different precue types were mixed than when they were blocked. In fact, it appears that mixing static and dynamic precues has no detrimental effect on the use of dynamic precues but is detrimental for static precues.

\section{Differences Between Static and Dynamic Precues}

Time course of attention effects. It is clear from these experiments that static and dynamic MEPs function quite differently in this paradigm with respect to the effects of advance knowledge of the actual precue. It is not 
known at this time whether a dynamic MEP will function in the same way as a static MEP in the time course of attention effects. A static MEP results in a slow rise in the accuracy-SOA curve that does not decline with long SOAs. In fact, the curve looks much like that of a central precue (Chastain, 1996). Here, in the experiments with motion (Experiments 3, 4, and 5), it was not possible to use short SOAs because of the time needed to produce apparent motion. In further research, the time needed for the motion precue should be shortened so that the shape of the early accuracy-SOA curve can be determined. Also, longer SOAs should be used to determine whether or not there is a decline with dynamic MEPs at long SOAs, as there is with static SEPs.

Latency to respond to the precue. The differences found among static precue types may be explained largely by the difference in the time needed to localize the unique singleton. It was shown that the more rapidly responses were made to the indicated location, the more accurate was identification of the target in the cued location (Figure 6). Even though the number of precues was relatively small, the negative correlation was large.

This relationship was not the same for dynamic precues. When an additional 24 observers were given the latency task with the four dynamic precues (vertical lines in horizontals, horizontal in verticals, vertical in verticals, and horizontal in horizontals), the latency (RT) and accuracy measures were in the same direction, not inverse. Thus, it appears that the negative relationship between latency to respond with the precued location and accuracy in target identification occurs only with static precues. Of course, accuracy differences for the dynamic precues were small and may preclude any consistent relationship with the latency measure.

\section{Conclusions}

These data demonstrate that advanced knowledge of the feature that designates an MEP facilitates identification of target orientation when that feature is presented as a static discontinuity. In contrast, when the feature is presented as a dynamic discontinuity, advance knowledge of the precue character has no facilitatory effect. Thus, bottom-up information for the static MEP is insufficient for best performance, but it is sufficient for the best performance for a dynamic MEP. The difference between mixed and blocked conditions for the static MEPs show that attention is not automatically elicited by these features.

It is obvious from these data that the attentional system is not merely tuned to static or dynamic discontinuities in this paradigm. As in so much of the attention literature, a simple dichotomy cannot describe the effects when tested in diverse paradigms.

\section{REFERENCES}

Bacon, W. F., \& EgEth, H. E. (1994). Overriding stimulus-driven attentional capture. Perception \& Psychophysics, 55, 485-496.
CAVE, K. R., \& WolfE, J. M. (1990), Modeling the role of parallel processing in visual search. Cognitive Psychology, 22, 225-271.

Chastain, G. (1996). Multiple-element line segment precues: Orientation and location effects on attention. Perception \& Psychophysics, 58, 1015-1025

Chastain, G., \& Cheal, M. L. (in press). Automatic versus directed attention with single-element and multiple-element precues. Visual Cognition.

ChEAL, M. L. (1997). Understanding diverse effects of visual attention with the VAP-Filters metaphor. Consciousness \& Cognition, 6, 348362.

Cheal, M. L., \& Gregory, M. (1997). Evidence of limited capacity and noise reduction with single-element displays in the locationcuing paradigm. Journal of Experimental Psychology: Human Perception \& Performance, 23, $51-71$.

Cheal, M. L., \& LyON, D. R. (1989). Attention effects on form discrimination at different eccentricities. Quarterly Journal of Experimental Psychology, 41A, 719-746.

Cheal, M. L., \& LyON, D. R. (1992a). Attention in visual search: Multiple search classes. Perception \& Psychophysics, 52, 113-138.

ChEAL, M. L., \& LyON, D. R. (1992b). Benefits from attention depend on the target type in location-precued discrimination. Acta Psychologica, 81, 243-267.

Cheal, M. L., \& Lyon, D. R. (1994). Allocation of attention in texture segregation, visual search, and location-precuing paradigms. Quarterly Journal of Experimental Psychology, 47A, 49-70.

Cheal, M. L., Lyon, D. R., \& GotTlob, L. R. (1994). A framework for understanding the allocation of attention in location-precued discrimination. Quarterly Journal of Experimental Psychology, 47A, 699-739.

Cheal, M. L., Lyon, D. R., \& Hubbard, D. C. (1991). Does attention have different effects on line orientation and line arrangement discrimination? Quarterly Journal of Experimental Psychology, 43A, 825-857.

Colegate, R. L., Hoffman, J. E., \& Eriksen, C. W. (1973). Selective encoding from multielement visual displays. Perception \& Psychophysics, 14, 217-224.

Folk, C. L., Remington, R. W., \& JohnSTon, J. C. (1992). Involuntary covert orienting is contingent on attentional control settings. Journal of Experimental Psychology: Human Perception \& Performance, 18, 1030-1044.

Folk, C. L., Remington, R. W., \& WRight, J. H. (1994). The structure of attentional control: Contingent attentional capture by apparent motion, abrupt onset, and color. Journal of Experimental Psychology: Human Perception \& Performance, 20, 317-329.

Hillstrom, A. P., \& Yantis, S. (1994). Visual motion and attentional capture. Perception \& Psychophysics, 55, 399-411.

Humphreys, G. W., \& BoucarT, M. (1997). Selection by color and form in vision. Journal of Experimental Psychology: Human Perception \& Performance, 23, 136-153.

JONIDES, J., \& YANTIS, S. (1988). Uniqueness of abrupt visual onset in capturing attention. Perception \& Psychophysics, 43, 346-354.

Joseph, J. S., Chun, M. M., \& Nakayama, K. (1997). Attentional requirements in a "preattentive" feature search task. Nature, $\mathbf{3 8 7}, 805$. 807.

Kahneman, D., \& Treisman, A. (1984). Changing views of attention and automaticity. In R. Parasuraman, R. Davies, \& J. Beatty (Eds.), Varieties of attention (pp. 29-61). New York: Academic Press.

Livingston, M., \& HuBEL, D. (1988). Segregation of form, color, movement, and depth: Anatomy, physiology, and perception. Science, 240, 740-749.

Maljkovic, V., \& Nakayama, K. (1994). Priming of pop-out: I. Role of features. Memory \& Cognition, 22, 657-672.

Müller, H. J., Heller, D., \& Ziegler, J. (1995). Visual search for singleton feature targets within and across feature dimensions. Perception \& Psychophysics, 57, 1-17.

MülLER, H. J., \& RABBitT, P. M. A. (1989). Spatial cuing and the relation between the accuracy of "where" and "what" decisions in visual search. Quarterly Journal of Experimental Psychology, 41 A, 747-773. 
Nakayama, K., \& Mackeben, M. (1989). Sustained and transient components of focal visual attention. Vision Research, 29, 16311647.

POSNER, M. I. (1980). Orienting of attention. Quarterly Journal of Experimental Psychology, 32, 3-25.

Posner, M. I., \& COHEN, Y. (1984). Components of visual orienting. In H. Bouma \& D. G. Bowhuis (Eds.), Attention \& performance $X$ (pp. 531-556). Hillsdale, NJ; Erlbaum.

Prinzmetal, W., NuRachukU, I., Bodanski, L., Blumenfeld, L., \& Shimizu, N. (1997). The phenomenology of attention: 2. Brightness and contrast. Consciousness \& Cognition, 6, 372-412.

Shiffrin, R. M., \& Schneider, W. (1977). Controlled and automatic human information processing: II. Perceptual learning, automatic attending, and general theory. Psychological Review, 84, 127-190.

Shiu, L., \& Pashler, H. (1994). Negligible effect of spatial precuing on identification of single digits. Journal of Experimental Psychology: Human Perception \& Performance, 20, 1037-1054.

Theeuwes, J. (1991). Cross-dimensional perceptual selectivity. Perception \& Psychophysics, 50, 184-193.

Theeuwes, J. (1992). Perceptual selectivity for color and form. Perception \& Psychophysics, 51, 599-606.

TheEuwes, J. (1994). Stimulus-driven capture and attentional set: Selective search for color and visual abrupt onsets. Journal of Experimental Psychology: Human Perception \& Performance, 20, 799-806.

THEeUwes, J. (1995). Abrupt luminance change pops out; abrupt color change does not. Perception \& Psychophysics, 57, 637-644.

TodD, S., \& Kramer, A. F. ( 1994 ). Attentional misguidance in visual search. Perception \& Psychophysics, 56, 198-210.
Treisman, A. (1988). Features and objects: The fourteenth Bartlett memorial lecture. Quarterly Journal of Experimental Psychology, 40A, 201-237.

Treisman, A. M., \& Gelade, G. (1980). A feature-integration theory of attention. Cognitive Psychology, 12, 97-136.

WoLFE, J. M. (1994). Guided Search 2.0: A revised model of visual search. Psychonomic Bulletin \& Review, 1, 202-238.

Wolfe, J. M., Cave, K. R., \& Franzel, S. L. (1989). Guided search: An alternative to the feature integration model for visual search Journal of Experimental Psychology: Human Perception \& Perfor mance, 15, 419-433.

Wolfe, J. M., Yu, K. P., Stewart, M. I., Shorter, A. D., FriedmanHILL, S. R., \& CAVE, K. R. (1990). Limitations on the parallel guidance of parallel search: Color $\times$ color and orientation $\times$ orientation conjunctions. Journal of Experimental Psychology: Human Perception \& Performance, 16, 879-892.

YANTIS, S. (1993). Stimulus-driven attentional capture. Current Directions in Psychological Science, 2, 156-161.

\section{NOTE}

1. We thank Jeremy Wolfe for suggesting (1) comparison with the Müller et al. (1995) data and (2) the idea of the bottom-up ceiling effect.

(Manuscript received February 4, 1997; revision accepted for publication July 20, 1997.) 